\title{
Social Connectedness and Flourishing: The Mediating Role of Hopelessness
}

\author{
Bahtiyar Eraslan-Capan \\ Department of Psychological Counseling and Guidance, Anadolu University, Turkey
}

Copyright $(2016$ by authors, all rights reserved. Authors agree that this article remains permanently open access under the terms of the Creative Commons Attribution License 4.0 International License

\begin{abstract}
In recent years, positive psychology has focused on flourishing; a combination of social and emotional well-being. For flourishing to function optimally, social environments as well as hopeful future expectation are crucial. It can be inferred that social connectedness and hope might be predictor of flourishing in early adulthood. This study aims at investigating the mediating effect of hopelessness on social connectedness and flourishing among university students. The participants were 260 university students $\left(52.7 \%\right.$ female, $47.3 \%$ male; $M_{\text {age }}=21.8$ yr., $\mathrm{SD}=0.99)$ who filled a questionnaire package, consisting the Social Connectedness Scale, the Beck Hopelessness Scale, and the Flourishing Scale. The hypothesis tested the mediation effects of hopelessness between social connectedness and flourishing using structural equation modeling. The results of the analysis revealed the mediating role of hopelessness between social connectedness and flourishing. Findings were discussed in line with relevant literature and conclusions were made.
\end{abstract}

Keywords Flourishing, Hopelessness, Social Connectedness, Positive Psychology

\section{Introduction}

Positive psychology studies have contributed to a broad understanding of individuals' well-being [1]. Flourishing, defined as the combination of social, emotional and psychological well-being [2], is a popular concept that has recently been discussed in positive psychology $[3,4,5,6]$. It is also defined as a state in which a person behaves psychologically and socially well [7]. Therefore, it is a socio-psychological concept influenced by social and psychological factors [8]. Previous studies suggested a positive relationship between social relations, hope, life purposes in one's life and flourishing $[9,3,10]$. In this regard, this study aims to achieve a better understanding of flourishing by studying the impacts of social connectedness and hopelessness on flourishing.

\subsection{Flourishing}

In the past few decades, researches began to focus on what it means to flourish in life, searching for the presence of positive psychosocial functioning rather than solely the absence of mental illness [11]. Flourishing can be described as being within an optimal range of human functioning associated with wellness, generativity, performance, growth, and resilience $[12,13,5,4]$, conceptual structure of flourishing is composed of positive emotions, emotional stability, vitality, optimism, resilience, self-esteem, engagement, competence, meaning and positive relationships. The definition of flourishing is consistent with the World Health Organization's (WHO) mental health description [14]: "a state of well-being in which the individual realizes his or her own abilities, can cope with the normal stressors of life, and work productivity and fruitfully, and is able to make a contribution to his or her community" (p. 12). According to Diener et al. [15], to flourish is to have "meaning and purpose, supportive and rewarding relationships, [to be] engaged and interested [in one's life], contribute[ing] to the well-being of others, competency, self-acceptance, optimism and being respected" (p. 252). People who are flourishing are more likely to be satisfied with their lives, aware of their abilities and eager to achieve, thrive and make a meaningful contribution to society $[16,4$, 8]. In short, flourishing includes having social relations as well as positive personal characteristics.

Previous research has found that flourishing is highly related to emotional, psychological, and social well-being [3, 5]. In other studies, flourishing has been found to be positively related to personal development, positive relations with others, life purposes [17], suffering and positive effect [9], mindfulness, positive emotional reactivity [18], self-kindness, common humanity, and mindfulness [19], competency, relatedness, autonomy and self-acceptance [3]. In contrast, flourishing was found negatively-associated with maladaptive variables such as loneliness [3], depression [20, 21], self-judgment, isolation, and over-identification [19].

Flourishing is seen in relation to one's quality of life as a whole, rather than just positive emotions, the pursuit of 
pleasure, or feeling good about one's life [22]. Similarly flourishing is defined as a state in which one functions psychologically and socially well $[9,3,7]$. From a social aspect, flourishing has the features like relatedness, having supportive and rewarding relationships, contributing to the happiness of others, being respected by others $[3,23,4,24$, 6]. Flourishing individuals have more satisfactory interpersonal relationships in general, and it seems flourishing can enhance the personal resources in different situations [25]. For this reason, social connectedness can be seen as an important concept which has a meaningful influence on flourishing.

\subsection{Social Connectedness}

Social connectedness is conceptualized as one among the features of an individual self that reveals how a person judges his/her closeness with the social surroundings [26, 27]. It is associated with one's belief of self in relation to others. It is described as how one understands and views his/her closeness with others, the social and outside world [28].

Many studies have found that social connectedness is positively associated with the sense of belonging [29], personal meaning [30], life satisfaction [31], improved health status [32, 33], cognitive functioning [34] and well-being [35]. On the contrary, social connectedness is negatively correlated with depression and suicidal ideation [36], chronic loneliness, lower self-esteem, higher trait anxiety and greater social mistrust [27]. Accordingly, social connectedness is a favorable condition that moves an individual ahead in life.

Social connectedness involves in all aspects of social interaction including family, friends, and the community; and it refers to one's relationship with others in general. Social connectedness was found out to be correlated with trusted relationships with others, safe attachments, social competent, support accessible to an individual through social ties, less number of difficulties in the relationship with others, adopting characteristics of a social groups $[37,38,39,40$, 41]. People who have a high sense of connectedness feel themselves belonging to a family, friends or a social group and they define themselves as warm and positive $[39,27]$. These people also have a high level of self-esteem, self-worth, purpose and meaning in life since they receive social support and social acceptance from a close environment [42]. They have the ability to develop more meaningful relationships [43]. Lack of connection to others indicates absence of social support, weak interaction with the social system, or an awareness of separation from others [43]. Low connected individuals may report absence of meaningful and supportive relationships in their lives and as a result they may experience psychological distress $[44,45$, 41]. People who lack a sense of connectedness rarely have a sense of belongingness [27]. Low connected individuals may perceive their environment as pessimistic and cold, and their sense of self as negative [39, 27]. These findings suggest that low social connectedness leads to more pessimistic thoughts.

\subsection{Hopelessness}

Hopelessness is a thought process that comprises a pessimistic way of ascribing the future, and one's inability to change what the future brings. It is one's thinking of adverse events and incapability of changing the future [46], and this pessimistic view is considered as part of the cognitive triad, which is a feature of depression [47]. According to Beck [48], hopeless and depressive people attribute irrational thoughts to their experiences without building on an objective and rational base. From their negative experiences, they judge themselves negatively.

Individuals experiencing hopelessness see negative events in their future and are likely to care very little about the things that influence their future, since they do not expect good things to happen [49]. Hopeless people perceive little control over the events in their lives and believe that good things will not happen to them [50] because these individuals are not confident and they are self-depreciating, and are not able to see the ways of overcoming these roadblocks. Their life purposes and their motivation to reach the aim are low when compared to people with high hope [49, 51].

Hopelessness has an inverse influence on well-being by leading an individual to perceive himself and his environment negatively. Recent researches also show that low hopelessness is associated with the sense of flourishing and positive emotions, life satisfaction and subjective well-being $[52,53,54,55,10,56,57,58]$. Otherwise, hopelessness is related to depression, suicidal behaviors, lower subjective well-being [59] and higher negative emotions regarding with personal purposes in the life $[60,61$, $47,62,63,46,64]$.

One's social environment has an important impact on the development of hope and hopelessness. Researches emphasized that hope flourishes in a nurturing environment where psychological needs are met, and supportive parent and friend relationships exist during childhood and adolescent years $[65,66]$. They also suggest hopelessness flourishes in an environment where family-peer related interpersonal stress factors exist and adequate support lacks [67]. Social relations and social support cause hope and hopelessness during adolescence and young adult period. A study carried out on university students has shown that lack of support from a friend was related to hopelessness and depression [68]. The individuals who fail to receive positive support from their friends are seized by loneliness and feel hopeless about the others and their futures [27]. It is obvious that social environment has an important impact on one's perception towards herself/himself, others and their future, so it affects psychological well-being.

\subsection{Current Study}

University life coincides with a time when important developmental changes take place towards the end of 
adolescence and beginning of young adulthood. While adolescents try to adapt to a new and stressful life, they strive to fulfill their tasks related to occupation, academy, and personal development. During this period, their psychological and physical well-being, and displaying functions at an optimum level will help them adapt to their new environment and successfully fulfill their developmental tasks more easily. Previous studies showed that flourishing people feel good about them, are successful, regularly experience numerous positive emotions and make more contributions to society [8]. In addition, Peter et al. [69] found that college students who were flourishing had lower rates of depression and anxiety. According to Diener et al. [3], flourishing impacts well-being through assisting and reinforcing relationships, playing its part to the happiness of others and having values for living.

Previous studies carried out with university students revealed significant relationship between flourishing and social support, importance of relationships, life purpose [9], hope and optimism [10]. Kandaris [70] reported the mediating effect of hope between emotion-focused coping and flourishing. Keyes [8] suggested that flourishing includes positive emotions, psychological functioning and social functioning. Furthermore, previous studies revealed that lifelong hopelessness and lack of connectedness are related to other risk factors for suicidal behavior [61, 71, 47]. Thus, the research aimed to study the mediating effect of hopelessness on social connectedness and flourishing. The findings of this study will make a contribution to psychological counselling centers at universities and to the development of social connectedness, hope and flourishing of university students.

\section{Method}

\subsection{Participants and Procedure}

The research was carried out on a sample of 260 university students (137 females $(52.7 \%), 123$ males $(47.3 \%)$ from an average state university in Turkey. The average age of the respondents was 21.78 years, with a standard deviation of 0.99 . Of the participants, 60 (23\%) were first-year students, $61(23 \%)$ second-year students, 81 (32\%) third-year students, and $58(22 \%)$ fourth-year students. A convenience sample was used for this study. We explained the goals of the study to the students, and informed them that participation was voluntary and confidential. Participants responded to the items in the questionnaire package at their own pace and it took around 15 minutes to cover all the sections.

\subsection{Measuring Instruments}

Social Connectedness: Social connectedness was measured with the Social Connectedness Scale (SCS) developed by Lee and Robbins [26]. The SCS includes eight items. The responses to each of these items on a 6-point Likert scale range from 1 (strongly disagree) to 6 (strongly agree). Sample items include: "I feel disconnected from the world around me" and "catch myself losing all sense of connectedness with society". Summing across all eight items provides a total score for this scale. The Turkish version of SCS has been translated by Duru [72]. Turkish version has been confirmed as a one-dimensional structure and has proved a good internal reliability. In the present study, Cronbach alpha coefficient was found as .93.

Hopelessness: Hopelessness was measured with the Beck Hopelessness Scale (BHS) developed by Beck, Weissman, Lester and Trexler [73]. The BHS consists of 20 true-false items assessing the three major aspects of hopelessness; feelings about the future, loss of motivation, and expectations. The Turkish version of Beck Hopelessness Scale has been translated by Durak [74]. The Turkish version has proved a good internal reliability. In the present study, Cronbach alpha coefficient was found as .79.

Flourishing: Flourishing was measured with the Flourishing Scale (FS) developed by Diener and colleagues [3]. The FS consists of eight items. Each item was answered on a 7-point Likert scale ranging from 1 (strongly disagree) to 7 (strongly agree). Sample items include: "I am competent and capable in the activities that are important to me" and "I lead a purposeful and meaningful life". Summing across all eight items provides a total score for this scale. The Turkish version of SCS has been translated by Akin and Fidan [75]. Turkish version confirmed a one-dimensional structure and proved a good internal reliability. In the present study, Cronbach alpha coefficient was found as .89 .

\subsection{Data Analysis}

The researcher tested the mediation effects using structural equation modelling (SEM) conducted with Lisrel 9.1. A two-step procedure suggested by Anderson and Gerbing [76] was adapted to analyze the mediation effect in order to confirm the structural relations of the latent structured model. The measurement model was first tested to assess the extent to which each of the latent variables was represented by its indicators. If the measurement model is accepted, then study the mediational model via the maximum likelihood estimation. The fit indexes used in this study are (1) Chi-square $\left(\chi^{2}\right)$, (2) Comparative Fit Index (CFI), (3) Normed Fit Index (NFI), (4) Standardized Root-Mean-Square Residual (SRMR), and (5) Root Mean Square Error of Approximation (RMSEA). Chi square difference test $\left(\Delta \chi^{2}\right)$ a measure of model fit adjusted for parsimony [77] was used to determine which model was preferred. If the model comparison is significant, then the model with a smaller Chi square value will be preferred [78].

\section{Results}

\subsection{Preliminary Analyses}


Means, standard deviations, and bivariate correlations for all the latent variables are presented in Table 1. All correlations are statistically significant. The results revealed that hopelessness was negatively correlated with social connectedness, while positively correlated with flourishing. Furthermore, social connectedness was positively correlated with flourishing.

Table 1. Correlations and descriptive statistics of the study variables

\begin{tabular}{|l|c|c|c|c|}
\hline \multicolumn{1}{|c|}{ Variable } & 1 & 2 & Mean & SD \\
\hline 1. Social connectedness & - & & 38.63 & 7.56 \\
\hline 2. Hopelessness & $-.39^{* *}$ & - & 4.27 & 3.27 \\
\hline 3. Flourishing & $.31^{* *}$ & $.50^{* *}$ & 42.46 & 8.35 \\
\hline \multicolumn{5}{|c}{$p<.01$} \\
\hline
\end{tabular}

\subsection{Measurement Model}

Mediational analysis was conducted in two stages. Firstly, a measurement model was tested. Then, a structural model was used to test possible relationships among social connectedness, hopelessness, and flourishing. The measurement model included three latent factors (social connectedness, hopelessness and flourishing) and 19 observed variables. An initial test of the measurement model revealed a satisfactory fit to the data: $\chi^{2}(149, \mathrm{~N}=260)=$ 294.79, $p<.001$; CFI $=0.98$; NFI $=0.95$; $\mathrm{SRMR}=0.057$; RMSEA $=0.06190 \%$ C.I. $[0.051,0.072]$. All standardized factor loadings were significant at $p<.001$ and higher than .57 at least.

\subsection{Structural Model}

In the first step, the direct path from the predictor (social connectedness) to the dependent (flourishing) in the absence of mediator was significant, $\beta=0.41, p<0.01$. Then, the partially mediated model, which contained a mediator (hopelessness) and a direct path from social connectedness to flourishing, was tested. The partially meditational model showed a very good fit to the data: $\chi^{2}(149, \mathrm{~N}=260)=$ 294.79, $p<.001$; CFI $=0.98$; NFI $=0.95$; $\mathrm{SRMR}=0.057$; RMSEA $=0.06190 \%$ C.I. $[0.051,0.072]$. To find a best model, we tested the fully mediational model. Thus, the path was deleted and the fully mediated model was tested. The fully meditated model showed a satisfactory fit to the data: $\chi^{2}$ $(150, \mathrm{~N}=260)=301.06, p<.001 ; \mathrm{CFI}=0.97 ; \mathrm{NFI}=0.95$; $\mathrm{SRMR}=0.065 ; \mathrm{RMSEA}=0.062$ 90\%C.I. [0.052, 0.072] .

The Chi-square difference test between a partially mediated model and a fully mediated model was significant $\left(\Delta \chi^{2}=6.27, \mathrm{df}=1, p<0.05\right)$, which suggests that a partially mediated model was better. Also, partially mediated model's ECVI and AIC values (1.48 and 382.78, respectively) smaller than fully mediated model's ECVI and AIC values (1.49 and 385.20.78,), and partially mediated model was preferred (Figure 1).

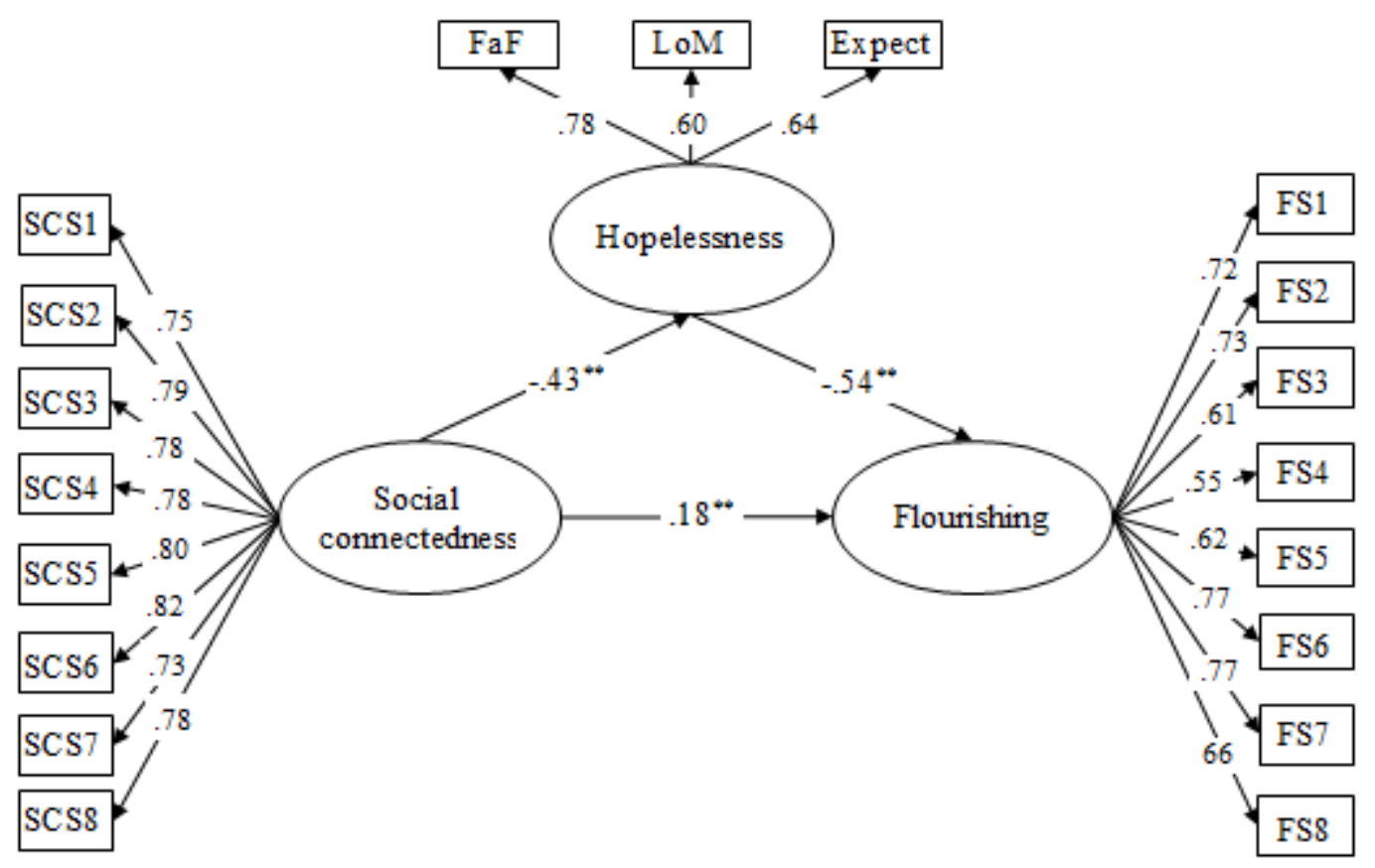

Figure 1. Standardized parameter estimates for the partially mediated structural model. Notes: $N=260 ;{ }^{* *} p<.01 ;$ FaF Feelings about the future; LoM Lost of motivation; Expect Expectation; SCS item of the Social Connectedness Scale; FS item of the Flourishing Scale 
Overall results indicated that the effect of social connectedness on flourishing was partially mediated by hopelessness. Social connectedness predicts flourishing through the hopelessness. That is to say, the positive relation between social connectedness and flourishing turns into a negative relation through hopelessness mediating variable. In short, a negative relation is seen between social connectedness-hopelessness-flourishing.

\section{Discussion}

The aim of this study was to study the mediating role of hopelessness in the relationship between flourishing and social connectedness. In this study, as expected, the results indicated that hopelessness partially mediated the relation between flourishing and social connectedness. Social connectedness predicts flourishing through hopelessness. In other words, individuals with low levels of social connectedness are likely to engage in hopelessness, which results in low flourishing.

This result is consistent indirectly with previous studies. Researchers agree that lack of relationship with others and hopelessness together increases the risk for lifelong suicidal thoughts and behaviors [62, 71, 46]. In addition, some researches express that hopelessness causes low well-being [64], low life satisfaction, depression and suicidal thoughts [59].

Different forms of social disruptions and lack of connectedness is found in research being directed to more hopelessness and despair [79]. Preliminary studies have shown that lack of connectedness pertains to lack of support accessible to an individual through social ties, poor interaction in to a social system, or an awareness of separation from others [43]. As individuals with a low level of social connectedness do not feel belonging to a group, they cannot get support from their environment and cannot share their feelings and thoughts [27]. These people generally live alone, they do not have the chance to receive feedback from their environment, so they do not know themselves and evaluate negatively as they perceive their potential lower than the available. In addition, these people view their surroundings as hostile, threatening, and unfriendly. The negative perception they have about themselves and others affects their perception of future in a negative way [27]. Low social connectedness people do not have life goals and motivation to reach these goals [79, 27], that is why, the individuals without social connectedness live hopelessness.

Hopelessness has been associated with diminished physical, psychological, mental, and spiritual health [80]. In a research carried out with general population, it is put forward that hopelessness becomes determinant of life satisfaction, depression and suicidal thoughts [59]. The research indicated that those who were hopeless had low satisfaction level, depression and suicidal thoughts. Hopelessness is also characterized by persistently negative feelings and expectations about the future as well as loss of motivation. A sense of hopelessness seems to lead to increasingly negative evaluations of new situations and less effective coping strategies; thus, the perception is that one will not accomplish anything meaningful [81]. They may hardly find new routes and lack the drive to implement pathways and pursue their goals [51].

University students maintain a life away from their families. Therefore, the social and emotional friendships they have are important in terms of their psychological health. During this period, they have to cope with adapting to a new and stressful university life and fulfill occupational, academic, emotional tasks and social development duties. The students who do not have a social bond face difficulty in adapting to the new environment as they do not get any support from their circles in occupational, academic or emotional challenges. The students, who fail to establish a social relation, cannot feel to belong to a group and lack a social connectedness, have low awareness about them and their future plans as they do not get enough social support and approval from their environment. In addition, these students have pessimistic viewpoints as they do not have any friends to tell about themselves and their future plans and to get a feedback. Those students who fail to overcome these difficulties, adapt to university life, and do not have a clear future plan and a life purpose feel themselves unsuccessful and useless. Therefore, these individuals' socially and psychologically well-being - shortly flourishing - goes down.

\section{Conclusions}

Establishing a sincere relationship and being sociable are among the fundamental developmental tasks in early adulthood. This study, which investigated mediating role of hopelessness between social connected and flourishing, indicated that hopelessness partially mediated the association between flourishing and social connectedness. On the other hand, it can be seen that, social connectedness predicts flourishing through hopelessness. It can be inferred that social connectedness and hopelessness are the significant determinants of the flourishing.

This study has got limitations. In the first place, the participants of the study are university students in Turkey, so it might be difficult to make a generalization regarding the university students from anywhere in the world. Therefore, studies that examine the relationships between social connectedness, hopelessness and flourishing in different cultures and different sample groups may help generalize the results of this study. In the second place, the study intended to develop a model instead of testing it, so findings of the study tend to be more explanatory in nature. Thirdly, as structural equation modeling is used, it is difficult to provide further explanation in the relationship between variables.

Though there are limitations, one can find important contributions from the study. The study results can help university student affairs and counseling centers in that 
clients coming with cases of disconnectedness, hopelessness and low flourishing could be better understood. Moreover, it is vital for administration and counseling professionals to look for ways of prevention and intervention to address social disconnectedness, hopelessness and low flourishing in university. For instance, student affairs staff might keep on developing preventive programs, seminars and lectures that can affect social connectedness, hope and flourishing. Due to the fact that hopelessness foretells risk behaviors in youth population [79], the results of the study are believed to have suggestions for intervention programs with this population. In these intervention programs, sub-titles such as goal setting, self-esteem and self-confidence development, realization of success and gaining social skills can be suggested. The students with high level of hopelessness can be guided to individually take psychological assistance. In addition, the students with low social connectedness and high level of hopelessness should be encouraged to voluntarily attend social service activities and efforts of student clubs can be reassigned. Accordingly, the results of the study show that it is important to work on changing the social environment of youths.

\section{REFERENCES}

[1] K.W. Springer, \& R. M. Hauser. An assessment of the construct validity of Ryff's Scales of psychological well-being: Method, mode, and measurement effects, Social Science Research, 35 (4), 1080-1102, 2006.

[2] C. L. M. Keyes. Toward a science of mental health. In S. J. Lopez, \& C. R. Snyder (Eds.), Oxford Handbook of Positive Psychology, Oxford University Press, New York, 89-95, 2009.

[3] E. Diener, D. Wirtz, W. Tov, C. Kim-Prieto, D. Choi, S. Oishi $\&$ R. Biswas-Diener. New well-being measures: Short scales to assess flourishing and positive and negative feelings, Social Indicators Research, 97, 143-156, 2010.

[4] F.A Huppert \& T.T.C. So. Flourishing across Europe: Application of a new conceptual framework for defining well-being, Social Indicators Research, 110, 837-861, 2013.

[5] C. L. M. Keyes. The mental health continuum: From languishing to flourishing in life. Journal of Health and Social Behavior, 43, 207-222, 2002.

[6] M.E.P. Seligman. Flourish, NY: Simon \& Schuster, New York, 2011.

[7] C.L.M Keyes \& J. Haidt. Flourishing: Positive psychology and the life well lived, Washington DC: American Psychological Association, 2002.

[8] C.L.M Keyes. Promoting and protecting mental health as flourishing: A complementary strategy for improving national mental health, American Psychologist, 62, 95-108, 2007.

[9] K.J. Byron. Human flourishing: An exploratory, grounded theory approach, Doctoral Dissertation, Graduate School of
Psychology, USA, 2011.

[10] M.W. Gallagher \& S.J. Lopez. Positive expectancies and mental health: Identifying the unique contributions of hope and optimism, The Journal of Positive Psychology, 4(6), 548-556, 2009.

[11] C.L.M. Keyes. Positive psychology: The study of that which makes life worthwhile', 2003.

[12] B.L. Fredrickson \& M. Losada. Positive affect and the complex dynamics of human flourishing, American Psychologist, 60 (7), 678-686, 2005.

[13] R.J. Larsen \& Z. Prizmic. Regulation of emotional well-being: Overcoming the hedonic treat mill, In M. Eid \& R.J. Larsen (Eds.), The Science of Subjective Well-being, Guilford Press, New York, 258-289, 2008.

[14] World Health Organization. Promoting mental health: Concept, emerging evidence, practice (Summary Report), Geneva, 2004.

[15] E. Diener, D. Wirtz, W. Tov, C. Kim-Prieto, D. Choi \& S. Oishi, S. New measures of wellbeing: Flourishing and positive and negative feelings, Social Indicators Research, 39, 247-266, 2009.

[16] N. Gokcen, K. Hefferon \& E. Attree. University students' constructions of 'flourishing' in British higher education: An inductive content analysis, International Journal of Wellbeing, 2(1), 1-21, 2012.

[17] B. B. Telef. The adaptation of psychological well-being into Turkish: A validity and reliability study. Hacettepe University Journal of Education, 28(3), 374-384, 2011.

[18] L.I. Catalino \& B.L. Fredrickson. A Tuesday in the life of a flourisher: The role of positive emotional reactivity in optimal mental health, Emotion, 11(4), 938-950, 2011.

[19] S.A Satici, R. Uysal \& A. Akın. Investigating the relationship between flourishing and self-compassion: A structural equation modeling approach, Psychologica Belgica, 4, 85-99, 2013.

[20] C.L.M. Keyes. Mental health and/or mental illness? Investigating axioms of the complete state model of health. Journal of Consulting and Clinical Psychology, 73, 539-548, 2005.

[21] A.M. Wood \& S. Joseph. The absence of positive psychological (eudemonic) well-being as a risk factor for depression: A ten-year cohort study, Journal of Affective Disorders, 122(3), 213-217, 2010.

[22] C.L. Keyes \& J. Annas. Feeling good and functioning well: Distinctive concepts in ancient philosophy and contemporary science, The Journal of Positive Psychology, 4(3), 197-201, 2009.

[23] M.J.C. Forgeard, E. Jayawickreme, M. Kern \& M.E.P. Seligman. Doing the right thing: measuring well-being for public policy, International Journal of Wellbeing, 1(1), 79-106, 2011.

[24] M.L. Kern, S.S. Della Porta \& H.S. Friedman. Lifelong pathways to longevity: Personality, relationships, flourishing, and health, Journal of Personality, 82(6), 472-484, 2014.

[25] M. Losada. The complex dynamics of high performance teams, Mathematical and Computer Modelling, 30, 9-10, 
179-192, 1999.

[26] R.M. Lee \& S.B. Robbins. Measuring belongingness: The social connectedness and social assurance scales. Journal of Counseling Psychology, 42, 232-241, 1995.

[27] R.M. Lee \& S.B. Robbins. The relationship between social connectedness and anxiety, self-esteem, and social identity, Journal of Counseling Psychology, 45, 338-345, 1998.

[28] R.M. Lee \& S. B. Robbins. Understanding social connectedness in college women and men. Journal of Counseling \& Development, 78, 108-115, 2000.

[29] B.M. Hagerty, J. Lynch-Sauer, K.L. Patusky, M. Bouwsema \& P. Collier, P. Sense of belonging: A vital mental health concept, Archives of Psychiatric Nursing, 6 (3), 172-177, 1992.

[30] B.M. Hagerty \& A. Williams. The effects of sense of belonging, social support, conflict, and loneliness on depression, Nursing Research, 48(4), 215-219, 1999.

[31] D.C. Siebert, E.J. Mutran \& D.C. Reitzes. Friendship and social support: The importance of role identity to aging adults, Social Work, 44(6), 522-533, 1999.

[32] L.F. Berkman, T. Glass, I. Brissette \& T.E Seeman. From social integration to health: Durkheim in the new millennium, Social Science \& Medicine, 51(6), 843-857, 2000.

[33] T.E. Seeman, T.M. Lusignolo, M. Albert \& L. Berkman. Social relationships, social support, and patterns of cognitive aging in healthy, high-functioning older adults, Mac Arthur studies of successful aging, Health Psychology, 20(4), 243, 2001.

[34] A.J. Gow, A. Pattie, M.C Whiteman, L.J. Whalley \& I.J. Deary. Social support and successful aging: Investigating the relationships between lifetime cognitive change and life satisfaction, Journal of Individual Differences, 28(3), 103-115, 2007.

[35] P.E. Jose, N. Ryan \& J. Pryor. Does social connectedness promote a greater sense of well-being in adolescence over time? Journal of Research on Adolescence, 22(2), 235-251, 2012.

[36] R.K. Vanderhorst \& S. McLaren. Social relationships as predictors of depression and suicidal ideation in older adults, Aging \& Mental Health, 9(6), 517-525, 2005.

[37] E. Banai, M. Mikulincer \& P.R. Shaver. Self-object needs in Kohut's self psychology: Links with attachment, self-cohesion, affect regulation, and adjustment, Psychoanalytic Psychology, 22, 224-260, 2005.

[38] R.M. Lee, M. Draper \& S. Lee. Social Connectedness, dysfunctional interpersonal behaviors, and psychological distress: Testing a mediator model, Journal of Counseling Psychology, 48(3), 310, 2001.

[39] R.M. Lee, K.A. Keough \& J.D. Sexton. Social connectedness, social appraisal, and perceived stress in college women and men, Journal of Counseling \& Development, 80, 355-361, 2002.

[40] N.P. Moller, R.T. Fouladi, C.J. McCarthy, \& K.D Hatch. Relationship of attachment and social support to college students' adjustment following a relationship breakup, Journal of Counseling and Development, 81(3), 354, 2003.
[41] K.L. Williams \& R.V. Galliher. Predicting depression and self-esteem from social connectedness, support, and competence. Journal of Social and Clinical Psychology, 25, 855-874, 2006.

[42] P.A. Thoits. Volunteer identity salience, role enactment, and well-being comparisons of three salience constructs, Social Psychology Quarterly, 76 (4), 373-398, 2013.

[43] J.W. Kaminski, R.W. Puddy, D.M. Hall, S.Y. Cashman, A.E. Crosby \& A.G. Ortega. The Relative Influence of Different Domains of Social Connectedness on Self-Directed Violence in Adolescence, Journal of Youth and Adolescence, 39, 460-473, 2010.

[44] K.C. Townsend \& B.T. McWhirter. Connectedness: A review of the literature with implications for counseling, assessment, and research, Journal of Counseling \& Development, 83(2), 191-201, 2005.

[45] J. Kabat-Zinn. Full catastrophe living, using the wisdom of your body and mind to face stress, pain, and 1llness, 15th Anniv. Ed, New York, Bantam Dell, 2005.

[46] S.S. Daniel \& D.B. Goldston. Hopelessness and lack of connectedness to others as risk factors for suicidal behavior across the lifespan: Implications for cognitive-behavioral treatment, Cognitive and Behavioral Practice, 19, 288-300, 2012.

[47] A.T. Beck, A.J. Rush, B.F. Shaw \& G. Emery. Cognitive Therapy of Depression, Guilford, New York, 1979.

[48] A.T. Beck. The current state of cognitive therapy, a 40- year retrospective. Archieves of General Psychiatry, 62, 953-959, 2005.

[49] J.R. Alverson. A model of hopelessness, belongingness, engagement, and academic achievement, Doctoral dissertation, The University of Alabama, 2014.

[50] C.R. Snyder, K.L Rand \& D.R. Sigmon. Hope theory, Handbook of Positive Psychology, 257-276, 2002.

[51] C.R. Snyder, K.K. Wrobleski, S.C. Parenteau \& C.J. Berg. Hope and hopelessness, Handbook of Primary Care Psychology, 145-155, 2004.

[52] A. Demirli, M. Türkmen \& R.S Arık. Investigation of dispositional and state hope levels' relations with student subjective well-being, Social Indicator Resources, 120, 601-613, 2015.

[53] M. Diehl, E.L. Hay \& K.M. Berg. The ratio between positive and negative affect and flourishing mental health across adulthood, Aging \& Mental Health, 15, 882-893, 2011.

[54] B.L. Fredrickson. The role of positive emotions in positive psychology: The broaden and build theory of positive emotions, American Psychologist, 56(3), 218-226, 2001.

[55] B.L. Fredrickson, S. Brown, M.A Cohn, A. Conway \& J. Mikels. Positive emotions build personal resources and predict future subjective wellbeing, Paper Presented at the Sixth Annual Meeting of the Society for Personality and Social Psychology, New Orleans, LA, 2005.

[56] N. Park, C. Peterson \& M.P. Seligman. Reply strengths of character and well-being: A closer look at hope and modesty, Journal of Social and Clinical Psychology, 23(5), 628-634, 2004. 
[57] C. Peterson \& M.E.P. Seligman. Character strengths and virtues: A handbook and classification, Washington, D.C., APA Press and Oxford University Press, 2004.

[58] K.R Vacek, L.D. Coyle \& E.M. Vera. Stress, self-esteem, hope, optimism, and well-being in urban, ethnic minority adolescents, Journal of Multicultural Counseling and Development, 38, 99-111, 2010.

[59] K. Haatainen, A. Tanskanen, J. Kylmaä, K. Honkalampi, H. Koivumaa-Honkanen, J. Hintikka \& H. Viinamaki. Factors associated with hopelessness, a population study, International Journal of Social Psychiatry, 50(2), 142-152, 2004.

[60] L.Y. Abramson, L.B. Alloy, M.E. Hogan, W.G. Whitehouse, B.E Gibb, B.L. Hankin \& M.M Cornette. The hopelessness theory of suicidality, in T. E. Joiner, \& M. D. Rudd (Eds.), Suicide Science, expanding the boundaries, Boston, Kluwer Academic, 2000.

[61] A.T. Beck. Beyond Belief: A theory of modes, personality, and psychopathology, in P. Salkovskis (Ed.), Frontiers of Cognitive Therapy, Guilford, New York, 1-25, 1996.

[62] J.J. Mann. Neurobiology of suicidal behavior, Neuroscience, 4, 819-828, 2003.

[63] C.R. Snyder, J. Cheavens \& S.C. Sympson. Hope: An individual motive for social commerce, Group Dynamics, Theory, Research and Practice, 1(2), 107, 1997.

[64] M. Sisask, A. Vamık, K. Kölves \& K. Konstabel, D. Wasserman. Subjective psychological well-being (WHO-5) in assessment of the severity of suicide attempt. Nord $\mathbf{J}$ Psychiatry, 62(6), 431-5, 2008.

[65] M.D. Resnick, P.S Bearman, R.W. Blum, K.E. Bauman, K.M. Harris, K. M., J. Jones, ... \& J.R. Udry. Protecting adolescents from harm: Findings from the national longitudinal study on adolescent health, Jama, 278 (10), 823-832, 1997.

[66] M.J. Van Ryzin. Protective factors at school: Reciprocal effects among adolescents' perceptions of the school environment, engagement in learning, and hope, Journal of Youth and Adolescence, 40 (12), 1568-1580, 2011.

[67] J.L. Hamilton, S.L. Connolly, R.T. Liu, J.P. Stange, L.Y. Abramson \& L.B. Alloy. It gets better: Future orientation buffers the development of hopelessness and depressive symptoms following emotional victimization during early adolescence, Journal of Abnormal Child Psychology, 43(3), 465-474, 2014.

[68] M. Soyer, S. Avcı \& T. Akınc1. The examining some health behaviors and hopelessness of adolescents, VII. Presented to the National Counseling and Guidance Congress, Malatya, Turkey, 2003.

[69] T. Peter, L.W. Roberts \& J. Dengate. Flourishing in life: An empirical test of the dual continua model of mental health and mental illness among Canadian university students, International Journal of Mental Health Promotion, 13(1), 13-22, 2011.

[70] K. Kandaris. The moderating effect of hope on the relationship between emotional approach coping and flourishing in college students, College of Education Theses and Dissertations, 2013.

[71] T.E. Joiner. Why People Die by Suicide. Cambridge, MA: Harvard University Press, 2005.

[72] E. Duru. The Adaptation of Social Connectedness Scale Turkish Culture, Eurasian Journal of Educational Research, 26, 85-94, 2007.

[73] A.T. Beck, A. Weissman, D. Lester \& L. Trexler. The measurement of pessimism: The Hopelessness Scale, Journal of Consulting and Clinical Psychology, 42, 861-865, 1974.

[74] A. Durak. Beck Umutsuzluk Ölçeği'nin Geçerliği Üzerine Bir Çalışma [A validity study of the Beck Hopelessness Scale]. Unpublished Master Thesis, Ankara University, Turkey, 1993.

[75] A. Akın \& M. Fidan. The validity and reliability of the Turkish version of the Flourishing Scale, Paper presented at the 3rd International Conference on New Trends in Education and Their Implications (ICONTE-2012), April, 26-28, Antalya, Turkey, 2012.

[76] J.C. Anderson \& D.W. Gerbing. Structural equation modeling in practice: A review and recommended two-step approach, Psychological Bulletin, 103(3), 411, 1988.

[77] K.P. Burnham \& D.R. Anderson. Model selection and multimodel inference: A practical information-theoretic approach, Springer Science \& Business Media, 2002.

[78] R.C. MacCallum, M.W. Browne \& H.M. Sugawara. Power analysis and determination of sample size for covariance structure modeling, Psychological Methods, 1(2), 130-49, 1996.

[79] J.M. Bolland, B.E. Lian \& C.M. Formichella. The origins of hopelessness among innercity African-American adolescents, American Journal of Community Psychology, 36 (3-4), 293-305, 2005.

[80] Y. Yildirim, O.O. Sertoz, M. Uyar, et al. Hopelessness in Turkish cancer inpatients: the relation of hopelessness with psychological and disease-related outcomes. European Journal of Oncology Nursing, 13(2), 81-86, 2009.

[81] I.A. Avci, A. Okanli, E. Karabulutlu \& N. Bilgili. Women's marital adjustment and hopelessness levels after mastectomy. European Journal of Oncology Nursing, 13(4), 299-303, 2009. 